\title{
PELANGGARAN ETIKA PROFESI BANKIR DALAM DIMENSI KEJAHATAN PERBANKAN
}

\author{
Ida Nurhayati ${ }^{1}$ dan Rita Farida ${ }^{2}$ \\ ${ }^{1}$ Jurusan Akuntansi, Politeknik Negeri Jakarta \\ ${ }^{2}$ Jurusan Teknik Sipil, Politeknik Negeri Jakarta \\ Email : ${ }^{1}$ ida.nurhayati@akuntansi.pnj.ac.id
}

\begin{abstract}
This research is part of my dissertation that discusses ethical violations including banking crimes, which are subtle (criminogenic). This study aims to explain that ethics can be used as a guideline in running banking activities in addition to the legal regulations that accompany banking activities. This research uses a qualitative approach using a model put forward by Graaf-Huberts (2008) that is "Monster Grid". Violation of ethics in banking crime is one form of white collar crime, as proposed by Sutherland, because the characteristics presented have been met by the perpetrators. First, the perpetrators all feel guilty, because such work has been long and repeatedly done. Second, they feel no harm to customers / community. Stay in good relationship with the victim, in this case the client. In this study, only to the point why ethics can be used as guidance in running the profession of bankers?. This can happen, among others, because: 1.Lemahnya internal supervision; 2. Supervision should be integrated with non-formal factors, such as lifestyle factors, association, and community culture; 3. Not strictly adhered to with full awareness of the principles of professional code of ethics, because it is only the Principle of Bankers Code of Conduct.
\end{abstract}

Keywords: dimension, banking crime, criminigenic

\begin{abstract}
Abstrak
Penelitian ini bagian dari disertasi saya yang membahas tentang pelanggaran etika termasuk kejahatan perbankan, yang bersifat halus (criminogenic). Penelitian ini bertujuan untuk menjelaskan bahwa etika dapat dijadikan pedoman dalam menjalankan kegiatan perbankan selain peraturan hukum yang menyertai kegiatan perbankan. Penelitian ini menggunakan pendekatan kualitatif dengan menggunakan model yang dikemukakan oleh Graaf-Huberts (2008) yaitu "Monster Grid". Pelanggaran etika dalam kejahatan perbankan merupakan salah satu bentuk dari white collar crime, seperti dikemukakan oleh Sutherland (, karena ciri-ciri yang dikemukakan telah terpenuhi oleh para pelakunya. Pertama, para pelaku semuanya merasa tidak bersalah, karena pekerjaan seperti itu telah lama dan berulang kali dilakukan. Kedua, mereka merasa tidak merugikan nasabah/masyarakat.Tetap berhubungan baik dengan korbannya, dalam hal ini nasabahnya. Pada penelitian ini, hanya sampai pada sebab mengapa etika dapat dijadikan pedoman dalam menjalankan profesi bankir?. Hal tersebut dapat terjadi antara lain, karena: 1.Lemahnya pengawasan internal; 2. Pengawasan sebaiknya terintegrasi dengan faktor-faktor non formal, misalnya faktor gaya hidup, pergaulan, dan budaya masyarakat; 3. Belum ditaati secara ketat dengan penuh kesadaran prinsip-prinsip kode etik profesinya, karena hanya bersifat Prinsip Kode Etik Bankir.
\end{abstract}

Kata Kunci : dimensi, kejahatan perbankan, criminogenic

\section{PENDAHULUAN}

Perbankan, sebagai salah satu bagian dari bisnis keuangan dalam masyarakat. Ciri utama di dalam menjalankan bisnis perbankan adalah bersandarkan kepada kepercayaan. Kepercayaan tersebut seringkali menjadi sebuah momen yang dapat disalahgunakan oleh semua pihak dalam kegiatan operasional, mulai dari tingkatan karyawan sampai dengan manajemen, dengan berbagai modus operandi yang dapat merugikan masyarakat/nasabahnya. Penyalahgunaan kepercayaan tersebut merupakan kejahatan perbankan.

Mereka dalam melakukan kejahatan, karena ada kesempatan, penuh perhitungan, serta mengantisipasi kemungkinan-kemungkinan untuk menyelamatkan hasil kejahatannya apabila tertangkap. Modus untuk melakukannya berbeda dengan modus kejahatan konvensional, sedangkan nilai 
obyek pencuriannya sangat besar (Wiryosukarto, 2012).

Kasus pelanggaran dan kejahatan perbankan pada beberapa bank yang telah terjadi sebelum krisis ekonomi di Indonesia tahun 1997/1998, dapat dilihat ada tabel 1 .

Tabel 1. Data Kejahatan Perbankan Mabes POLRI Tahun 2011Bagian Pidana Khusus Bidang Ekonomi

\begin{tabular}{|c|c|c|c|}
\hline $\begin{array}{l}\text { Nama } \\
\text { Bank }\end{array}$ & $\begin{array}{c}\text { Kasus } \\
\text { \&Tahun }\end{array}$ & Nilai & Pelaku \\
\hline A & $\begin{array}{l}\text { Pemalsuan, } \\
\text { Pembobolan } \\
(2011)\end{array}$ & $\begin{array}{l}6 \text { juta } \\
\text { \$US }\end{array}$ & $\begin{array}{l}\text { Supervisor } \\
\text { kantor kas }\end{array}$ \\
\hline B & $\begin{array}{l}\text { Pemalsuan } \\
\text { tandatangan } \\
\text { pada slip } \\
\text { penarikan } \\
(2011) \\
\end{array}$ & $\begin{array}{l}\text { Rp } 18 \\
\text { miliar }\end{array}$ & $\begin{array}{l}\text { Customer } \\
\text { Service }\end{array}$ \\
\hline $\mathrm{C}$ & $\begin{array}{l}\text { Penggelapan } \\
\text { dana nasabah } \\
(2011)\end{array}$ & $\begin{array}{l}1,9 \mathrm{M} \\
\text { dan } \\
110.000 \\
\text { \$US }\end{array}$ & Head Teller \\
\hline $\mathrm{D}$ & $\begin{array}{l}\text { Penggelapan } \\
\text { dana nasabah } \\
(2011)\end{array}$ & $2,5 \mathrm{M}$ & $\begin{array}{l}\text { Kepala } \\
\text { Operasi }\end{array}$ \\
\hline $\mathrm{E}$ & $\begin{array}{l}\text { Penggelapan } \\
\text { dana nasabah } \\
(2011)\end{array}$ & $\begin{array}{l}16,63 \\
M\end{array}$ & $\begin{array}{l}\text { Senior } \\
\text { Relationship } \\
\text { Manager }\end{array}$ \\
\hline $\mathrm{F}$ & $\begin{array}{l}\text { Kecurangan } \\
\text { Investasi } \\
\text { Deposito } \\
(2011)\end{array}$ & $111 \mathrm{M}$ & $\begin{array}{l}\text { Kepala } \\
\text { Cabang }\end{array}$ \\
\hline
\end{tabular}

Sumber: Diolah dari Kompas.Com, 2011.

Dari data kejahatan perbankan tersebut di muka, menunjukkan bahwa di dalam kejahatan perbankan, baik yang terjadi di bank umum pemerintah maupun swasta, dengan berbagai macam kasus yang ada, memiliki nilai kerugian uang yang besar. Para pelakunya sebagian besar adalah orang dalam atau para bankir. Kasuskasus tersebut bukanlah kasus pertama (sebelum krisis ekonomi tahun 1997).

Tabel 2. Kasus Fraud (Kecurangan) Pada Perbankan 2014-2016

\begin{tabular}{|c|c|c|}
\hline No & Jenis Kasus & Persentase (\%) \\
\hline 1 & Kredit & 55 \\
\hline 2 & $\begin{array}{c}\text { Rekayasa } \\
\text { Pencairan Dana }\end{array}$ & 21 \\
\hline 3 & $\begin{array}{c}\text { Penggelapan } \\
\text { Dana }\end{array}$ & 15 \\
\hline 4 & Transfer Dana & 5 \\
\hline 5 & Pengadaan Aset & 4 \\
\hline
\end{tabular}

Sumber : Ariyanti, 2016
Data tersebut di atas menujukkan bahwa fraud/kecurangan terbesar pada bidang perkreditan yang mencapai 55\% mengindikasikan bahwa kredit masih merupakan bagian yang dapat mendorong seseorang atau beberapa orang untuk melakukan fraud.

Cohen, at all (2010) menemukan ciri kepribadian tampaknya menjadi faktor utama risiko penipuan. Auditor harus mengevaluasi etika manajemen melalui komponen dari TPB (Plan Behavior Theory): penilaian sikap, norma subyektif, kontrol perilaku yang dirasakan dan kewajiban moral. Yang diharapkan oleh Cohen dan kawan-kawannya, bahwa etika selalu dilaksanakan dan terus secara berkala di audit atau di evaluasi, menyesuaikan perkembangan profesi dan masyarakatnya, sehingga etikanya selalu up to date dan menjadi fleksibel.

Kelemahan fundamental di dunia perbankan tersebut dapat tercermin dari kualitas manajemen bank yang masih buruk, konsentrasi kredit pada pemilik Bank yang berlebihan, munculnya moral hazard, transparansi yang belum memadai serta kurang efektifnya pengawasan Bank oleh Bank Indonesia pada waktu itu (Maria, 2011).

Dalam pelanggaran perbankan bahkan sampai pada kejahatan perbankan, yang terjadi adalah suatu pelanggaran etika yang telah diketahui oleh para pelaku sebagai suatu pandangan, pedoman dalam berperilaku sehari-hari. Di sinilah etika hanya sampai pada taraf diketahui, namun di dalam mematuhinya atau menjalankannya bisa saja ada sesuatu hal yang menghalang-halangi atau membuat mereka menjadi tidak mematuhinya.

Belum menempatkan etika sebagai pedoman yang efektif, dan lebih menyentuh kepada nilai-nilai moral perilaku individu. Belum berfungsinya kontrol internal sebagai unsur penjeraan. Untuk menghidupkan kembali paradigma kepatuhan, dengan membangun secara teratur dan meninjau kembali nilai-nilai moral, etika dengan lebih menekankan 
pada menanamkan budaya kepatuhan yang selaras dengan nilai-nilai masyarakatnya pada kaum profesional bank.

Kejahatan oleh profesi sebagai salah satu bentuk dari kejahatan jabatan, yang dapat terjadi karena kaum profesional dalam menjalankan profesinya mempunyai hak khusus. Dalam hal ini peluang kaum profesional dapat menyalah gunakan keahliannya di dalam memberikan jasa pelayanannya kepada masyarakat yang membutuhkan keahlian profesional.

Belum ditempatkannya etika sebagai pedoman yang efektif, dan lebih menyentuh kepada nilai-nilai moral perilaku individu. Bahkan etika masih berada pada posisi yang dianggap dapat memecahkan masalah mengenai suatu kejahatan yang pelaksanaannya dianggap biaya tinggi (high cost), tidak efektif. Oleh karena itu, faktor apa saja yang dapat menghambat atau kendala bagi para bankir pelaku kejahatan dalam melaksanakan dalam menjalankan profesinya.

\section{METODE PENELITIAN}

Penelitian ini menggunakan pendekatan kualitatif, dimulai dengan mempelajari data sekunder yang berasal dari media sosial (internet) yang dipublikasikan oleh Bareskrim RI. Hal itu dilakukan agar dapat diketahui dengan pasti perkara kejahatan perbankan yang terjadi, seperti siapa, jabatannya, jenis kejahatannya, dan dimana napi pelaku kejahatan perbankan tersebut menjalani hukuman. Demikian juga data diperoleh melalui studi dokumen berupa berkas perkara pelanggaran dan kejahatan perbankan pada beberapa bank di Indonesia.

Data tersebut, terdiri dari 3 (tiga) jenis kejahatan perbankan, yaitu kejahatan di bidang perkreditan, kejahatan praktik bank dalam bank, dan kejahatan pemalsuan (Tabel 3.1). Dari ke tiga jenis kejahatan perbankan tersebut, 15 (lima belas) orang pelaku kejahatan perkreditan, 2 (dua) orang pelaku kejahatan praktik bank dalam bank dan 1 (satu) orang pelaku kejahatan pemalsuan. Dari berkasberkas perkara tersebut, disusun pertanyaan-pertanyaan penelitian sesuai dengan permasalahan dalam penelitian ini.

Penelitian ini dilakukan untuk mengetahui bagaimana dapat terjadi pengabaian terhadap etika, yang merupakan salah satu faktor yang mendorong bankir untuk melakukan pelanggaran. Untuk itu, merujuk pada teori meodologi yang dilakukan oleh Clinard-Quinney (1972) dengan mengemukakan 5 (lima) dimensi sebagai aspek yang mempengaruhi orang untuk melakukan kejahatan. Dalam hal ini yaitu aspek Hukum dan Pelanggaran yang dipilih pelaku (Legal Aspect of Selected Offenses), aspek karir pelaku kriminal (Criminal Career of Offender), aspek dukungan kelompok dari pelaku kriminal (Group Support of Criminal Behavior), hubungan antara perilaku sah dan kriminal (Correspondence between Criminal and Legitimate Behavior), dan reaksi sosial dan proses hukum (Societal Reaction and Legal Processing). Kemudian dari Clinard-Quinney tersebut, dikombinasikan dengan penelitian yang dilakukan oleh Graaf dan Huberts (2008) yang disebut dengan metode " Monster Grid ", yang mengkategorisasikan menjadi 3 (tiga) antara kejahatan korupsi dengan berbagai macam pejabat publik sebagai pelakunya, kepribadian pelakunya, dan hubungan antara penyuap dengan koruptor. Sedangkan pada penelitian ini, terfokus pada beberapa jenis kejahatan perbankan yang dilakukan oleh para bankir.

Pada penelitian yang terkait dengan sutu profesi, hubungan antara peneliti dan subyek atau karyawan-asisten melibatkan kekuatan dan kepercayaan. Kekuasaan yang disahkan oleh kepercayaan, keahlian, pelatihan dan peran ilmu 
pengetahuan dalam masyarakat modern. Beberapa masalah etika melibatkan penyalahgunaan kekuasaan.

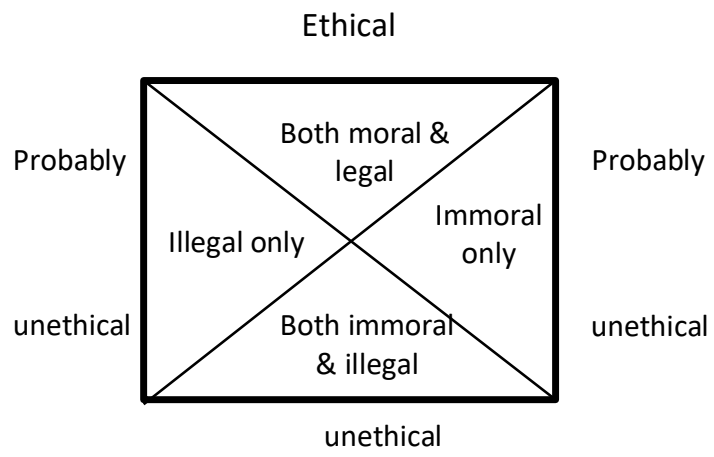

Sumber: Neuman, 1997

Pada gambar di atas menunjukkan bahwa untuk perilaku etis, dilakukan terhadap pilihan antara perilaku bermoral dan perilaku yang sah. Sedangkan perilaku tidak etis dijumpai pada pilihan perilaku tidak bermoral dan tidak etis. Untuk kemungkinan perilaku tidak etis, hanya perilaku pelanggaran hukum dan hanya perilaku tidak bermoral. Jelasnya bahwa untuk perilaku etis, meliputi perilaku bermoral dan tidak melanggar ketentuan formal.

Kekuatan hubungan antara peneliti dan subyek, karyawan atau asisten melibatkan kepercayaan. Eksperimen, survei, direktur atau penelitian penyidik memiliki kekuatan relatif terhadap subjek atau asisten. Otoritas peneliti untuk melakukan penelitian, diberikan oleh masyarakat profesional dan masyarakat yang lebih luas, disertai dengan tanggung jawab untuk dibimbing, dilindungi, dan diawasi kepentingan rakyat yang sedang dipelajari.

Peneliti mencari bimbingan etis tidak sendirian. Ia dapat mencari ke beberapa sumber: rekan-rekan profesional, komite penasehat etika di sebuah perguruan tinggi atau lembaga, kode etik dari asosiasi profesional, dan tulisan-tulisan tentang etika dalam penelitian (Neuman, 1997).

Dimensi teoritis Clinard-Quinney tersebut terintegrasikan dalam model “
Monster Grid” Graaf-Huberts (2008), yaitu:

Termasuk dalam lima dimensi tersebut adalah beragam fenomena yang terkait dengan kejahatan, yaitu, formulasi dan administrasi hukum pidana, pengembangan orang dan perilaku yang dapat didefinisikan sebagai kriminal, dan reaksisosial terhadap perilaku. Lima dimensi dengan dasar asumsi tipologi tertentu dari teori sistem perilaku kriminal.

\section{HASIL DAN PEMBAHASAN}

Ada 3 (tiga) jenis kejahatan perbankan yang penulis temukan, melalui data primer dan sekunder yaitu wawancara dengan 5 (lima) informan yang merupakan pelaku pelanggaran etika dan kejahatan perbankan yang sedang menjalani hukuman penjara, dan 13 (tiga belas) pelaku, penulis dapatkan dari data sekunder.

Tabel 3.Kategorisasi Kejahatan Perbankan Oleh Bankir

\begin{tabular}{|c|c|c|c|}
\hline No & Jenis Kejahatan & $\begin{array}{c}\text { Jumlah } \\
\text { Kasus }\end{array}$ & $\begin{array}{c}\text { Jumlah } \\
\text { Pelaku }\end{array}$ \\
\hline 1 & Perkreditan & 9 & 15 \\
\hline 2 & $\begin{array}{c}\text { Praktik Bank } \\
\text { Dalam Bank }\end{array}$ & 2 & 2 \\
\hline 3 & Pencatatan Palsu & 1 & 1 \\
\hline \multicolumn{2}{|c|}{ Total } & $\mathbf{1 2}$ & $\mathbf{1 8}$ \\
\hline
\end{tabular}

Sumber: Diolah, 2014.

Pejabat korporasi maupun profesi bankir, yang pekerjaannya mengelola keuangan nasabah atau masyarakat, yang telah melanggar ketentuan kerjanya, melanggar kepercayaan masyarakat, meskipun wujud kepercayaannya berbeda-beda. Seperti halnya profesi yang lain, seperti pejabat publik, juga diberi kepercayaan untuk melayani kepentingan masyarakat umum, sedangkan bankir diberi kepercayaan khusus mengelola keuangan masyarakat. Kesemuanya itu dapat dikategorikan sebagai pelanggaran etika dan kejahatan dalam pekerjaan atau profesi.Unsur kepercayaan di sini menjadi sesuatu yang sangat penting, mengingat 
mereka bekerja atas amanat rakyat/masyarakat bagi (pejabat publik) dan profesi bankir berdasar atas kepercayaan nasabah.

Pelanggar dalam pekerjaan dan profesi biasanya menganggap diri mereka sebagai warga negara terhormat, bukan sebagai penjahat. Karena pelaku berada dalam pekerjaan yang sah, sulit untuk membayangkan bahwa setiap kegiatandalam pekerjaan yang bisa menjadi fakta kejahatan .Ini konsepsi nonpidana diri adalah salah satu elemen penting dalam bentuk kejahatan. Mereka yang melanggar kepercayaan keuangan, seperti penggelap, dapat terlibat dalam perilaku seperti itu hanya ketika mereka bisa menggambarkan perilaku mereka sendiri dengan cara yang memungkinkan mereka untuk menyesuaikan pendapat mereka tentang diri mereka sebagai orang-orang terpercaya dengan konsep mereka tentang diri mereka sebagai pengguna dana yang dipercayakan atau properti. Pelanggar ini mendefinisikan situasi mereka dengan rasionalisasi yang memungkinkan mereka untuk menganggap mereka sebagai pelanggaran dasarnya bukan kriminal. Mereka berpikir perilaku mereka hanya sebagai "pinjaman", dibenarkan oleh kondisi yang tidak biasa atau masalah nonsharable yang dapat diselesaikan dengan posisi mereka melanggar kepercayaan (Quinney, 1979).

Clinard dan Yeager merujuk pandangan Clark dan Hollinger (1977) yang megatakan bahwa, norma-norma korporasi dalam menjalankan bisnis mungkin bertentangan norma etika dan norma hukum. Jalinan antara normanorma korporasi dengan tingkah laku tidak etis, norma-norma sosial, dan pelanggaran hukum mungkin terjadi pada suatu korporasi, terutama pada pengambilan keputusan (Mustofa, 2010). Para manajemen sebagai pengambil keputusan telah melanggar norma-norma, etika, dan kode etik bankir, sehingga tindakannya merugikan nasabah, yang dalam hal ini sebagai masyarakat pengguna jasa perbankan. Sesungguhnya masyarakat yang menyetorkan dananya kepada bank (nasabah) tersebut sebagai wujud kepercayaannya dalam pengelolaan keuangan mereka. Namun disalah gunakan kepercayaan tersebut, sehingga dapat merugikan nasabah. Karena jika masyarakat sudah tidak percaya terhadap bank sebagai lembaga keuangan yang mengelola dana masyarakat, hal itu dapat sistem mengganggu perbankan.

Secara umum kejahatan profesional bukan bagian dari hukum pidana. Itu bukan dari definisi hukum, melainkan perilaku penjahat profesional adalah terhormat dari penjahat yang lainnya. Itu adalah cara kejahatan dilakukan yang ditentukan dari karakter perilaku para profesional. Pelaku kejahatan profesional, yang dikategorikan seperti penipuan dari masing-masing kategori hukum seperti kecurangan/penipuan, kemudian kenyataanya diasosiasikan dengan peraturan perundang - undangan. Kejahatan profesional, sebagian besar, adalah konstruksi sosiologis dan bukan kategori hukum (Clinard-Quinney, 1972).

Praktik pelanggaran kepercayaan, dengan cara memanipulasi korban tanpa melalui kekerasan terhadap korban dalam situasi dari ketidak jujuran dalam rangka untuk mengambil keuntungan. Korban adalah orang-orang yang mempercayai pelaku karena ketidak tahuannya, dalam hal yang berhubungan dengan tugas profesinya. Dengan demikian, maka semua pelanggaran dan kejahatan yang berhubungan dengan " pelanggaran kepercayaan" yang dilakukan oleh profesional, dalam hal ini adalah para bankir, maka terjadi "pelanggaran etika". Karena dalam kejahatan profesional, sebagian besar adalah konstruksi sosiologis dan bukan kategori hukum (Clinard-Quinney, 1972).

Pada kasus kejahatan perbankan lainnya yang sering disebut praktik bank dalam, para pelaku biasanya telah diberi kepercayaan. Seperti halnya pada 
kejahatan perbankan lainnya, mereka juga mempunyai jabatan, pengalaman bekerja di bidang perbankan sudah cukup lama. Secara umum hampir sama ciri pelakunya dan pelanggaran yang dilakukan dengan kejahatan perbankan lainnya, hanya modusnya yang berbeda. Pelaku dalam praktik bank dalam bank, biasanya pelaku dapat menguasai nasabah, hubungannya sangat dekat dengan nasabah, dan sangat mempercayainya. Karena pendekatan awal yang sangat baik, meyakinkan, itulah yang disalah gunakan oleh pelaku untuk menguasai nasabah, termasuk uangnya. Oleh karena itu para nasabah tidak merasa dirugikan, karena hak-haknya tetap diberikan oleh pelaku.

Kejahatan praktik bank dalam bank, memang secara langsung tidak merugikan para nasabah, dan yang secara langsung dirugikan adalah banknya. Namun jika hal tersebut terus berlangsung, selain mengurangi pendapatan perusahaan (bank) karena keuntungan dari penyetoran dana para nasabah tidak menjadi aset bank, sehingga dana yang masuk ke bank tidak semestinya, dan itu mengurangi kemampuan modal dan aset bank. Kepada para nasabah, seolah-olah tidak menderita kerugian, namun jaminan terhadap keuangan nasabah dan hak-hak lainnya sebagai nasabah bank, tidak diperoleh secara maksimal, karena secara resmi sebenarnya para nasabah bukan menjadi nasabah bank yang mereka maksud. Hal inilah sebenarnya yang tidak terlihat dan tidak diketahui oleh kebanyakan masyarakat/nasabah bank, jika para bankir melakukan praktik seperti itu.

Etika profesi, sebagai pedoman para profesional dalam hal ini para bankir untuk mematuhi dan melaksanakan pedoman tata cara mereka dalam menjalankan profesinya. Etika profesi tersebut diwujudkan dalam bentuk Kode Etik, yaitu Kode Etik Bankir. Dalam hal bankir telah melanggar Kode Etik, maka dapat dikatakan telah melanggar etika profesinya. kejahatan oleh profesional dalam kapasitasnya sebagai kaum profesional selalu berhubungan dengan pelanggaran kepercayaan, maka pelanggaran ini dapat dilihat sebagai bentuk tipu daya yang bersifat khusus.

Tabel 4.Dimensi Perilaku Kriminal ClinardQuinney

\begin{tabular}{|c|c|}
\hline $\begin{array}{c}\text { Dimensi } \\
\text { Perilaku } \\
\text { Kriminal } \\
\end{array}$ & Penjelasan \\
\hline $\begin{array}{l}\text { Aspek hukum } \\
\text { dan etika yang } \\
\text { dilanggar }\end{array}$ & $\begin{array}{l}\text { Definisi kejahatan adalah adalah } \\
\text { perilaku manusia yang diciptakan } \\
\text { oleh agen-agen yang berwenang } \\
\text { dalam suatu masyarakat yang } \\
\text { terorganisir secara politik. Hukum } \\
\text { yang mengatur tentang kejahatan } \\
\text { dirumuskan oleh segmen } \\
\text { masyarakat yang memiliki kekuatan } \\
\text { untuk mengakomodir keinginan } \\
\text { mereka dalam suatu kebijakann } \\
\text { publik, sehingga hukum pidana } \\
\text { mengatur perilaku yang dianggap } \\
\text { mengancam kelas penguasa. }\end{array}$ \\
\hline $\begin{array}{l}\text { Karir kriminal } \\
\text { dari pelaku }\end{array}$ & $\begin{array}{l}\text { Perilaku pelaku dibentuk oleh } \\
\text { seberapa jauh norma-norma dan } \\
\text { kegiatan yang ditetapkan yang } \\
\text { menjadi bagian dari perkembangan } \\
\text { kejahatan individu. Perkembangan } \\
\text { peran sosial pelaku, termasuk peran } \\
\text { dia bermain, tentang konsep diri, } \\
\text { perkembangan dalam kegiatan } \\
\text { kriminal, dan identifikasi dengan } \\
\text { kejahatan. }\end{array}$ \\
\hline $\begin{array}{l}\text { Dukungan } \\
\text { kelompok } \\
\text { terhadap } \\
\text { perilaku } \\
\text { kejahatan }\end{array}$ & $\begin{array}{l}\text { Perilaku pelaku didukung oleh } \\
\text { norma-norma kelompok dari mana } \\
\text { mereka berasal. Beberapa yang } \\
\text { didefinisikan sebagai kejahatan } \\
\text { menurut pola normatif dipelajari } \\
\text { dalam lingkungan sosial dan } \\
\text { budaya tertentu. Dukungan } \\
\text { kelompok perilaku kejahatan } \\
\text { bervariasi sesuai dengan asosiasi } \\
\text { pelaku dengan perbedaan norma- } \\
\text { norma yang telah menyatu dalam } \\
\text { kelompok sosial. }\end{array}$ \\
\hline $\begin{array}{l}\text { Hubungan } \\
\text { antara perilaku } \\
\text { jahat dengan } \\
\text { perilaku yang } \\
\text { sah }\end{array}$ & $\begin{array}{l}\text { Dalam konteks ini, orang } \\
\text { mengembangkan dan melakukan } \\
\text { tindakan-tindakan yang relatif } \\
\text { memiliki kemungkinan } \\
\text { didefinisikan sebagai kejahatan. }\end{array}$ \\
\hline $\begin{array}{l}\text { Reaksi sosial } \\
\text { dan proses } \\
\text { hukum }\end{array}$ & $\begin{array}{l}\text { Perilaku kejahatan pada umumnya } \\
\text { didefinisikan bervariasi dalam } \\
\text { berbagai jenis dan jumlah reaksi } \\
\text { yang mereka terima dari } \\
\text { masyarakat. Reaksi sosial berkisar } \\
\text { dari tingkat persetujuan atau } \\
\text { ketidak setujuan terhadap kebijakan } \\
\text { prosedur sanksi. Perlakuan yang } \\
\text { diberikan dan pelaksanaannya } \\
\text { untuk setiap jenis kejahatan berbeda } \\
\text { hukuman formalnya }\end{array}$ \\
\hline
\end{tabular}

Sumber : Clinard-Quinney, 1972 
Pola dalam modus pelanggaran dan kejahatan ini ada beberapa unsur seperti unsur, pemalsuan, pencurian dan penggelapan, pelanggaran kewenangan, dan jabatan. Oleh karena itu cara seperti ini sering dilakukan oleh pimpinan yang secara kewenangan lebih mudah dilakukan.

\section{KESIMPULAN DAN SARAN}

Pejabat korporasi maupun profesi bankir, yang pekerjaannya mengelola keuangan nasabah atau masyarakat, yang telah melanggar ketentuan kerjanya, melanggar kepercayaan masyarakat, meskipun wujud kepercayaannya berbeda-beda. Seperti halnya profesi yang lain, seperti pejabat publik, juga diberi kepercayaan untuk melayani kepentingan masyarakat umum, sedangkan bankir diberi kepercayaan khusus mengelola keuangan masyarakat. Kesemuanya itu dapat dikategorikan sebagai pelanggaran etika dan kejahatan dalam pekerjaan atau profesi.Unsur kepercayaan di sini menjadi sesuatu yang sangat penting, mengingat mereka bekerja atas amanat rakyat/masyarakat bagi (pejabat publik) dan profesi bankir berdasar atas kepercayaan nasabah.

\section{DAFTAR PUSTAKA}

Adzani.2012. Etika Perbankan. Diakses di http://aladzaniart.blogspot.com.html pada Februari 2015.

Armando, Lopez, et al. 2008. Postconviction Self: Comparing White Collar Probationers And Street Crime Probationers. The University of Texas at San Antonio

Brody G. Richard and Kiehl, Kent A. 2010.From White-Collar Crime To Red-Collar Crime. Journal of Financial Crime 17. 3:351-364.

Cohen, Jeffrey, etc. 2010. Corporate Fraud and Managers' Behavior: Evidence from the Press: JBE.Journal of Business Ethics, suppl. Supplement $95: 271-$

315.

Cressey, Ray, Donald. 1953. Other People's Money: A Study In The Social Psychology of Embezzlement.Glencoe, Illinois: The Free Press.

Croall, Hazel 2001.Understanding White Collar Crime. BuckinghamPhiladephia: Open University Press.

Ermongkonchai, Phongstorn. 2010. Understanding Reasons for Employee Unethical Conduct in Thai Organizations: A Qualitative Inquiry. Contemporary Management Research6. 2: 125140.

Graaf and Huberts. 2008. Portraying the Nature of Corruption Using an Explorative Case Study Design. Public Administrationn Review. Vol 68. No. 4. Pp640-653.

Hansen, Laura. 2009. Corporate Financial Crime: Social Diagnosis and Treatment. Journal of Financial Crime 16. 1: 28-40. 2009

Heminway, Joan MacLeod. "Does Sarbanes-Oxley Foster the Existence of Ethical Executive Role Models in the Corporation?"Journal of Business and Technology Law, 2008. Vol 3: 221.

Mustofa, M. 2010. KleptokrasiPersekongkolan Birokrat-Korporat Sebagai Pola White Collar Crime di Indonesia. Jakarta: Kencana Prenada Media Group.

Quinney, Richard and Marshal B Clinard. 1972.Criminal Behavior System A Typology.Second Edition. Chapel Hill, Nort Carolina: Madison, Wisconsin.

Quinney, 1968. White Collar Criminal. The Offender in Business and The Profession-Edited, with introduction and notes, by Gilber Geis-Atherton Press New York. 
Sutherland, E.H. 1983. White Collar

Crime. With an Introduction by Gilbert Geiss and Colin Goff. New Haven and London. Yale University Press.

Yeager, Marshal B Clinard and Peter C. 1980.Corporate Crime. New York: The Free Press.

Zhang, Q. 2009.Study on Fraud Risk Prevention of Online Banks. Sch. of Inf. Manage\&Eng. (pp. 181-184). Shanghai: Univ. of Finance \&Econ. 